\title{
The Effect of Chlorella vulgaris on Lipid Profile Wistar Strain Rats (Rattus norvegicus Berkenhout, 1769) Under Induced Stress
}

\author{
FARAH NADIA KARIMA ${ }^{1}$, MULYATI ${ }^{1}$ \\ ${ }^{1}$ Laboratory of Animal Physiology, Faculty of Biology, Universitas Gadjah Mada \\ Jl. Teknika Selatan, Sekip Utara, Yogyakarta, Indonesia. 55281 \\ *Email: farahfarahnk@gmail.com
}

Received 06 February 2019; Received in revised form 30 March 2019;

Accepted 28 June 2019; Available online 30 June 2019

\begin{abstract}
Stress is a psychiatric/psychological disorder characterized by a sense of disability, despair, anhedonia, decreased activity, and pessimism. Stress can affect the physiological condition of the body with symptoms of lipid metabolism disorders. Chlorella vulgaris is a microalgae that is known to have the potential as an alternative antidepressant drug. The study was conducted to determine the lipid profile of blood wistar strain rats after stress induction and the effect of administration of Chlorella vulgaris on blood lipid profiles of stress-induced wistar rats. This research is an experimental study using 5 treatments with 25 models of Rattus norvegicus wistar strain, 2 months old. The treatment group consisted of 1 control group, 1 stress group, and 3 groups of treatment variations, namely the treatment of antidepressant medication, the treatment of administration of cultivated Chlorella vulgaris, and the treatment of commercial Chlorella. Stress induction is carried out by treatments that given to the rats randomly, namely cold water, warm water, wet cage, dark-light cycle, and sound wave exposure for 40 days. Examination of blood lipid profiles was carried out on Day 0 after mice were acclimated, day 40 after rats were induced stress, and day 56 after rats were given treatment of cultivated Chlorella vulgaris. The results obtained were the stress conditions of the lipid profile of the wistar strain of rats which had increased were total cholesterol levels of the control group and triglyceride levels in all groups while those who had decreased were cholesterol levels other than the control group, HDL levels in all groups, and LDL levels all groups. Giving Chlorella vulgaris had effect on decreasing total cholesterol levels, triglyceride levels, and LDL levels along with increasing HDL levels.
\end{abstract}

Keywords: antidepressants; Chlorella vulgaris; lipid profile; stress; wistar

\section{INTRODUCTION}

Stress is a mood disorder signed by the feeling of inability, desperate, decreased activity, pessimism, anhedonia and sadness that interfere with someone life. If those symptoms are getting worse it can lead to coronary heart disease, atherosclerosis until suicide. Stress also related to high cholesterol level (Feroza in Wattoo et al., 2008; Balkan et al., 2004).

Chlorella vulgaris is known as high antioxidant producer. Chlorella is suspected to potentially affect lipid profiles because antioxidants can stimulate the increase of HighDensity Lipoprotein (HDL) cholesterol which helps to fight Low Density Lipoprotein (LDL) cholesterol oxidation. Chlorella is simple-green microalgae that is not motile, eukaryotic, unicellular, and round. This kind also has high chlorophyll as having higher photosynthetic abilities compared to the higher plants (Das, 2015). Chlorella is known that can produce some kind of carotenoids like $\alpha$-carotene, $\alpha$ carotene, lutein, zeaxanthin, antheraxanthin, and violaxanthin (Fretes et al., 2012). Carotenoid in Chlorella is beneficial in stimulating the body's immunity, absorbing cholesterol, and preventing degenerative diseases such as coronary heart disease, cancer, and stroke (Wirosaputro \& Sumarlini, 2016). The benefit for health of carotenoid is known as antioxidant. Lutein is the most carotenoid contained in Chlorella. Beta-carotene is known to be inversely proportional to DC cardiovascular risk and certain cancers. $\alpha$ carotene dan $\beta$-carotene have additional benefits because it can be conversed as vitamin A, that includes the development and prevention of chronical diseases. The relation between carotenoid and cholesterol, most of researches already observe the effect of single carotenoid compound in membrane mechanical, cholesterol absorbent in intestine, 
and incorporation of cholesterol into liposomes (Ryu et al, 2014). $\beta$-carotene protects LDL from oxidation (Salem, 2015). Chlorella also a good food fiber source that affects to lymphatic cholesterol and triglyceride absorption, with improving intestine viscosities, change the competition of bile acids collection or produce fermented products in intestine (Queenan et al., 2014).

From the potency of Chlorella vulgaris as the alternative to reduce stress, this research conducted to know the lipid profile of white blood wistar strain rats than induced with stress.

\section{MATERIALS AND METHODS}

This research conducted in Research Laboratory and Integrated Observation of Gadjah Mada University Yogyakarta (LPPT UGM). Rats care and data collection conducted in LPPT UGM Unit IV while sampling test conducted in LPPT UGM Unit I.

This research is an experimental research using 5 treatments. Treatment group consist of 1 positive control group, 1 negative control group, and 3 treatment variation group of antidepressant amitriptyline medicine treatment, Chlorella sp. distribution treatment, and commercial Chlorella sp. distribution treatment, each of the groups consist of 5 tests (5 rats) so the total test animal needed was 25 of white blood wistar strain rats. The old variation treatment conducted for 28 days. Each group namely as code $\mathrm{K}=$ without treatment, $\mathrm{St}=$ stress, $\mathrm{St}-\mathrm{O}=$ stress with medicine control of Amitriptyline antidepressant with the dose of $2.25 \mathrm{mg} / \mathrm{kgBB}, \mathrm{St}-\mathrm{ChIB}=$ stress with Chlorella vulgaris with the dose of $153 \mathrm{mg} / \mathrm{kgBB}$, St$\mathrm{ChIK}=$ stress with Chlorella sp. commercial with the dose of $153 \mathrm{mg} / \mathrm{kgBB}$.

The acclimation of rats was carried out for 3 days. After acclimation, rats were induced by stress using several exposures to mild stressors. Among them were cold water treatment by means of rats inserted in a water tank with a water depth of $25 \mathrm{~cm}$ and a water temperature of $5^{\circ} \mathrm{C}$ for 3 minutes, Treatment of warm water, rats put in a water tank with a water depth of 25 $\mathrm{cm}$ and a water temperature of $45^{\circ} \mathrm{C}$ for 3 minutes. Treatment of wet cages, rats were placed in cages with wet bedding as high as 5 $\mathrm{cm}$. This treatment was given for 4 hours. Changes in the dark-light cycle, rats were exposed to light at night and placed in a dark place during the day. The treatment of sound wave exposure, rats exposed to ultrasonic sound for 1 hour. The treatment of the cage was tilted, the cage is tilted $45^{\circ}$ for 6 hours. The stressors given every day were 1-2 stressors and with a minimum exposure interval of 3 days for the same stressors.

The six stressor treatments were randomly assigned to mice until the results of the Sucrose Preference Test (SPT) analysis showed significant effect. On day 40, rats underwent glucose preference tests to determine the stress status of mice. On the 41 st day until day 56 , rats were treated with Chlorella vulgaris.

The main parameters observed in this study were lipid profiles which consisted of the levels of total cholesterol, triglycerides, LDL, and HDL. Measurement of these parameters was carried out three times, namely before being given stress induction (day 0), when the condition of the rats reached a stress status (day 40), and after completion of treatment (56 days). In addition to lipid profiles, weight measurements were also made, as well as a sucrose preference test to determine the level of anhedonia of rats as the main symptom of stress.

Sucrose Preference Test. This test started by conditioning the rats to two drinking bottle placed in its cage for 3 days. After 3 days, one of the bottles was filled by $2 \%$ of sucrose and the other filled by aquades. Then, both of the drinking bottles was taking out from its cage for 12 hours, after 12 hours both of the bottle served together. The bottle position was switched for every 12 hours and the sucrose and aquades consumption measured after 24 hours (Chu et al., 2016).

Lipid Profile Analysis. The blood sampling conducted for $1 \mathrm{~mL}$ through rats orbitalis sinus test (Rattus norvegicus Barkenhout, 1769) wistar strain was using microhematocrit and was placed in microwave. Then the analysis conducted. The lipid Profile scorecard consisted of total cholesterol level, triglyceride, LDL, and HDL. The measurement of total cholesterol level through enzymatic 
photometric method using glycerol phosphateoxydase (GPO). Meanwhile, the level of HDL and LDL scored using precipitation method.

Data analysis. The data collected was tabulated and analyzed using Microsoft Excel based on t-test: paired two sample for means to know the effect of the treatment to the parameter and the R-methods software based on One Way ANOVA test to know whether there is significantly difference or not between groups after treatment and post hoc continued test $(p<0.05)$ to know the group that significantly different.

\section{RESULT AND DISCUSSION}

Weight measurement result, sucrose Preference test, and wistar rats' lipid profile are shown in Figure 1 and Table 1.

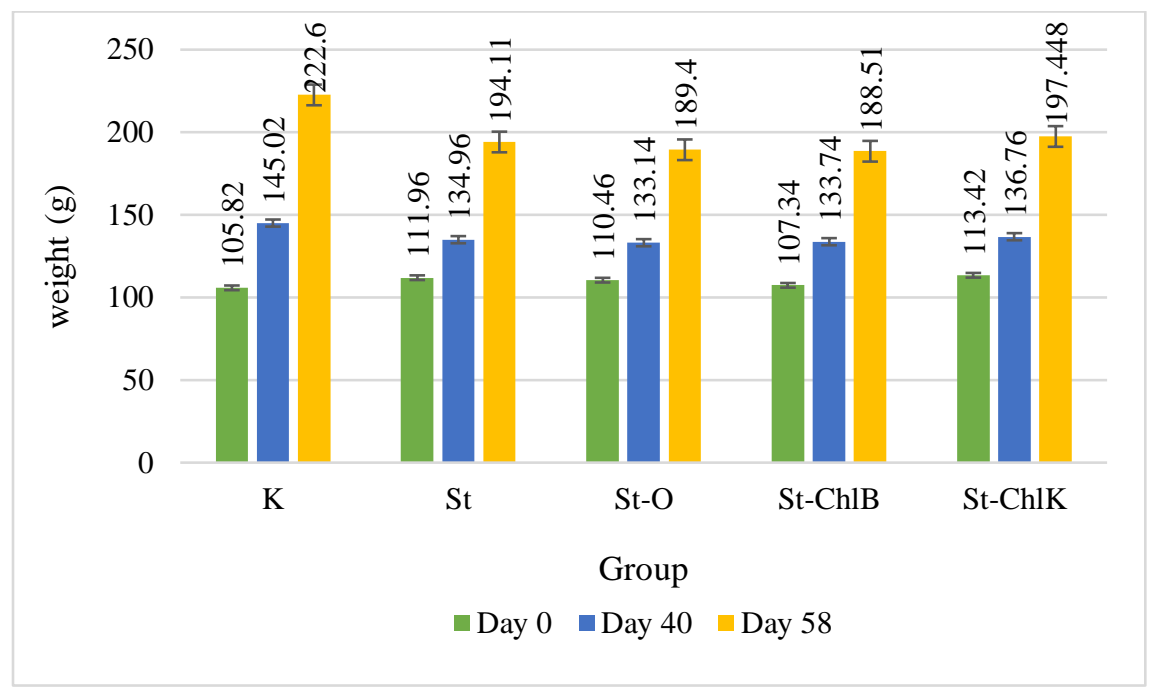

Figure 1. Rats weight average (Rattus norvegicus Berkenhout 1769) wistar strain in stress condition (day 40) and after Chlorella vulgaris treatment (day 58)

The following table lists the percentage of rat body weight increment of rats (Rattus norvegicus Berkenhout, 1769) wistar strain with the treatments appropriate their group.

Table 1. Percentage of body weight increment of rats (Rattus norvegicus Berkenhout 1769) wistar strain with the treatment of Chlorella vulgaris

\begin{tabular}{lcc}
\hline \multicolumn{1}{c}{ Treatment } & \multicolumn{2}{c}{ Weight } \\
\cline { 2 - 3 } & Difference $(\mathrm{g})$ & Percentage $(\%)$ \\
\hline Without treatment & 77.58 & 53 \\
\hline Stress & 59.15 & 44 \\
\hline Stress with antidepressant medicine & 56.26 & 42 \\
\hline Stress with Chlorella vulgaris cultivation & 54.77 & 41 \\
\hline Stress with Chlorella sp. commercial & 60.69 & 44 \\
\hline
\end{tabular}

Based on the analysis of the $\mathrm{T}$ Test, to find out the effect of giving treatment on body weight, the results showed that the administration of Chlorella sp. on the body weight of stress-induced rats showed a significant effect ( $p<0.05 ; p=0.00011)$. Weight loss can be caused by the direct effects of stress on the amount of food. Stress can increase protein catabolism and inhibit the use of food consumed during periods of stress, causing weight loss (Nagaraja et al., 2006).

Based on Table 1, it is shown that there was an increasement in body weight average in each treatment group when the condition experienced initial stress (40 days) and after being treated (58 days). All groups given stress induction had a smaller increase in body weight than the control group without stress induction. 
The control group had the highest percentage increase in body weight compared to other groups at $53 \%$. This was alleged because the metabolism of the control group was not affected by stress so that their eating activities were normal because they were not disturbed. The lowest percentage increase in body weight was owned by the stress group with cultivation of Chlorella vulgaris by $41 \%$. Seen from the stress indicator in Table 2, the stress group with Chlorella vulgaris cultivation had the lowest sucrose preference test $(54.8 \%)$ which means that the group was thought to have the highest anhedonia level. While the control group had the highest percentage increase in body weight $(53 \%)$ with the highest test of sucrose preference, which was $90.3 \%$. From these results, the administration of Chlorella vulgaris cultivation in the stress group for 14 days gave a fairly good influence in increasing body weight compared to the stress group given the antidepressant drug, the stress group given Chlorella sp. commercial, or stress groups.

Table 2. The test results of the sucrose preference of rats (Rattus norvegicus Berkenhout 1769) wistar strain with the treatment of Chlorella vulgaris

\begin{tabular}{lccccc}
\hline \multicolumn{1}{c}{ Period } & \multicolumn{5}{c}{ Group } \\
\cline { 2 - 6 } & $\begin{array}{c}\text { Treatment } \\
\text { control }\end{array}$ & Stress & $\begin{array}{c}\text { Stress with } \\
\text { Antidepressant } \\
\text { medicine }\end{array}$ & $\begin{array}{c}\text { Stress with Chlorella } \\
\text { vulgaris cultivation }\end{array}$ & $\begin{array}{c}\text { Stress with } \\
\text { Chlorella } \text { sp. } \\
\text { Commercial }\end{array}$ \\
\hline $\begin{array}{l}\text { Before stress } \\
\text { induction }\end{array}$ & 93.6 & 91.5 & 90.8 & 92.6 & 92.2 \\
\hline $\begin{array}{l}\text { After stress } \\
\text { induction }\end{array}$ & 90.3 & 57.5 & 56 & 54.8 & 55.8 \\
\hline $\begin{array}{l}\text { After treatment to } \\
\text { the groups }\end{array}$ & 93.6 & 2.1 & 90.2 & 89.9 & 92.2 \\
\hline
\end{tabular}

In this Sucrose Preference Test (SPT) of sucrose preference test was conducted to measure the rats' anhedonia level. Anhedonia includes as one of the main stress symptoms with the sign of reduced happiness. Naturally, rats' food and drink preferences were sweet food or sweet drink. So that the reduced preference of mice for these types of food can be assumed as the behavior of anhedonia (Serchov et al., 2016). SPT was performed three times, namely before stress induction, after stress induction, and after treatment.

Table 2 showed that the sucrose preference result before stress induction in all groups it was not too different, which was in the range of 9095\%. This shown that rats in each group have not experienced anhedonia because the sucrose preference was still close to $100 \%$. After 19 days given various types of stress in a group other than the untreated group, there was a decrease in sucrose preference. The results of the $\mathrm{T}$ sucrose preference test before and after stress induction showed that stress induction influenced sucrose preference in stress-induced rats $(\mathrm{p}<0.05 ; \mathrm{p}=0.0109)$. This indicates that the group of rats with stress induction treatment had experienced anhedonia. 


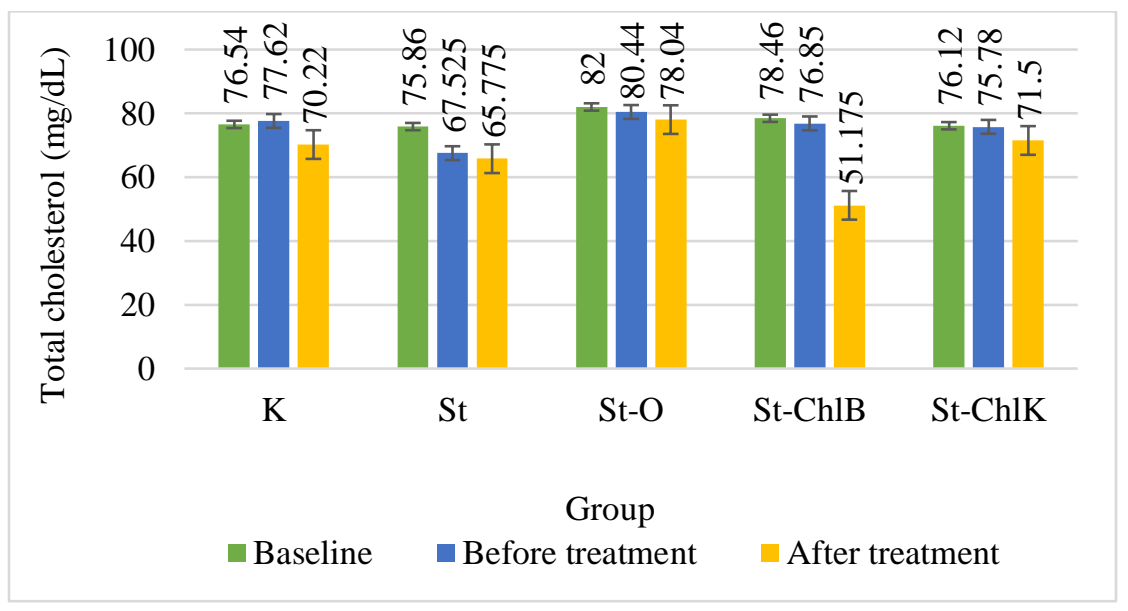

Figure 2. The mean total cholesterol level of rats (Rattus norvegicus Berkenhout, 1769) wistar strain with treatment with the treatment of Chlorella vulgaris

The following table lists the percentage in total cholesterol levels of rats (Rattus norvegicus Berkenhout, 1769) wistar strain with the treatments appropriate their group.

Table 3. The reduction percentage in total cholesterol levels of rats (Rattus norvegicus Berkenhout, 1769) wistar strain with the treatment of Chlorella vulgaris

\begin{tabular}{lcc}
\hline \multicolumn{1}{c}{ Treatment } & \multicolumn{2}{c}{ Total cholesterol level } \\
\cline { 2 - 3 } & Different (mg/dL) & Percentage $(\%)$ \\
\hline Without treatment & -7.4 & -10 \\
\hline Stress & -1.75 & -3 \\
\hline Stress with antidepressant medicine & -2.4 & -3 \\
\hline Stress with Chlorella vulgaris cultivation & -25.675 & -33 \\
\hline Stress with Chlorella sp. commercial & -4.28 & -6 \\
\hline
\end{tabular}

From the table 3, it can be seen that the highest cholesterol reduction level was owned by stress group with Chlorella vulgaris cultivation of $25.675 \mathrm{mg} / \mathrm{dL}$ (Table 5) with reduction percentage of $33 \%$ followed by control group (10\%), stress group with Chlorella sp. commercial (6\%), stress group (3\%), and stress group with antidepressant medicine (3\%). Then it was analyzed using One Way ANOVA test and resulted that total cholesterol level between groups has not significantly different $(\mathrm{p}>0.05-\mathrm{p}=0.53)$.

From the result above, also can be seen that the highest cholesterol reduction level owned by stress group with Chlorella vulgaris cultivation $(33 \%)$ while the lowest cholesterol reduction level $(3 \%)$ owned by group that induced by stress without treatment and group that induced by stress with antidepressant medicine treatment (3\%). Stress stimulates the activation of the hormone cortisol in response to stress. Cortisol stimulates stress from fat storage triglycerides which results in increases in free fatty acids (FFA) and cholesterol.

The percentage of cholesterol reduction level in stress group with Chlorella vulgaris cultivation was in line with the research conducted by Shibata et al. (2001) and Lee et al. (2008) that Chlorella can reduce animals' cholesterol level because of the antioxidant in Chlorella. Chlorella also plays an important role in inhibiting the absorption of fat in animal intestines (Shibata et al., 2001; Lee et al., 2008). In the stress-induced group without any treatment, the percentage of the lowest cholesterol level was reduced. This can occur because of stress from fat storage triglycerides which results in an increase in cholesterol thought to continue without a supplement to control the process. 


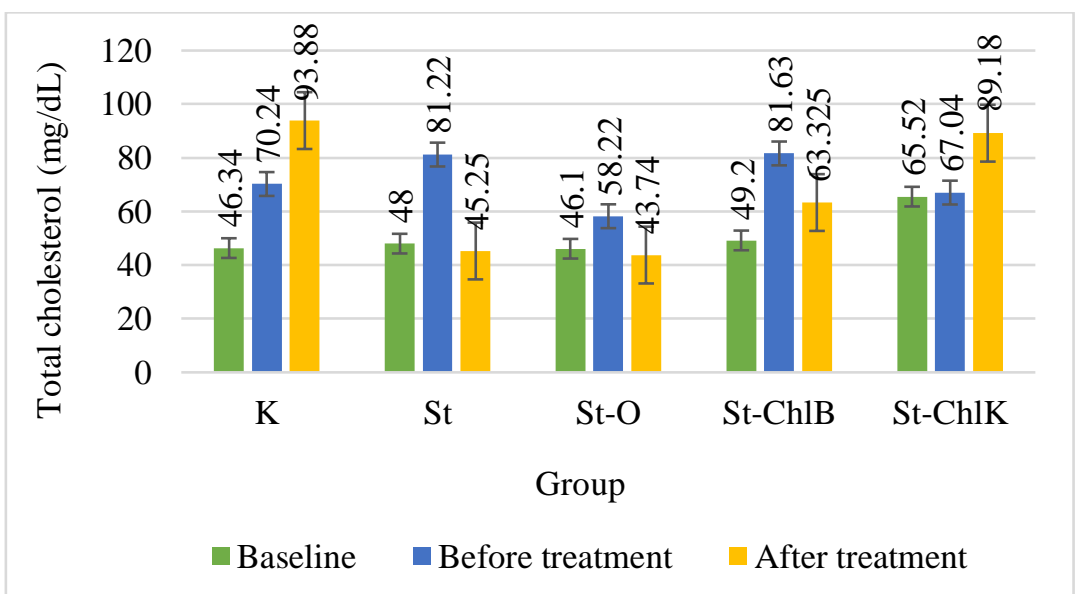

Figure 3. The mean of triglyceride level of rats (Rattus norvegicus Berkenhout, 1769) wistar strain with the treatment of Chlorella vulgaris

The following table lists the percentage of rat triglyceride levels (Rattus norvegicus
Berkenhout, 1769) wistar strain with the treatments appropriate their group.

Table 4. The percentage of rat triglyceride levels (Rattus norvegicus Berkenhout, 1769) wistar strain with the treatment of Chlorella vulgaris

\begin{tabular}{lcc}
\hline \multicolumn{1}{c}{ Treatment } & \multicolumn{2}{c}{ Total triglyceride levels } \\
\cline { 2 - 3 } & Different (mg/dL) & Percentage (\%) \\
\hline Without treatment & 23.64 & 34 \\
Stress & -35.975 & -44 \\
Stress with antidepressant medicine & -14.48 & -25 \\
Stress with Chlorella vulgaris cultivation & -18.305 & -22 \\
Stress with Chlorella sp. commercial & 22.14 & 33 \\
\hline
\end{tabular}

(-) indicates reduction

The highest triglyceride reduction level happened in the stress group of $35,98 \mathrm{mg} / \mathrm{dL}$ (Table 4) with reduction percentage of $44 \%$, followed by stress group with antidepressant medicine $(25 \%)$ and stress group with Chlorella vulgaris cultivation (22\%). From the results obtained it can also be seen that there was an increase in the highest triglyceride levels in the control group (34\%) and followed by the stress group with Chlorella $s p$. commercial (33\%). After analyzed using One Way ANOVA it resulted that the highest triglyceride level between group experienced significant difference in increment and reduction $(p<0,05 ; p=0,00141)$. Then post hoc further testing was carried out to find out which groups were significantly different. The results obtained from the test showed that the control group was significantly different from the stress group with antidepressant drugs, the stress group with Chlorella vulgaris cultivation, and the stress group with Chlorella sp. commercial but not significantly different from the stress group.

The percentage of triglyceride reduction level experienced by stress group (44\%), stress with antidepressant medicine (25\%) and stress with Chlorella vulgaris cultivation $(22 \%)$. The percentage of triglyceride levels reduce in the stress group with Chlorella vulgaris cultivation happened presumably because Chlorella contains omega-3 fatty acids which were included in the Polyunsaturated Fatty Acid (PUFA) group which can affect the decrease in triglyceride levels (Connor, 2000; Park and Harris, 2003). Chlorella has more PUFA content than other types of microalgae such as Spirulina (Otles \& Pire, 2001). 


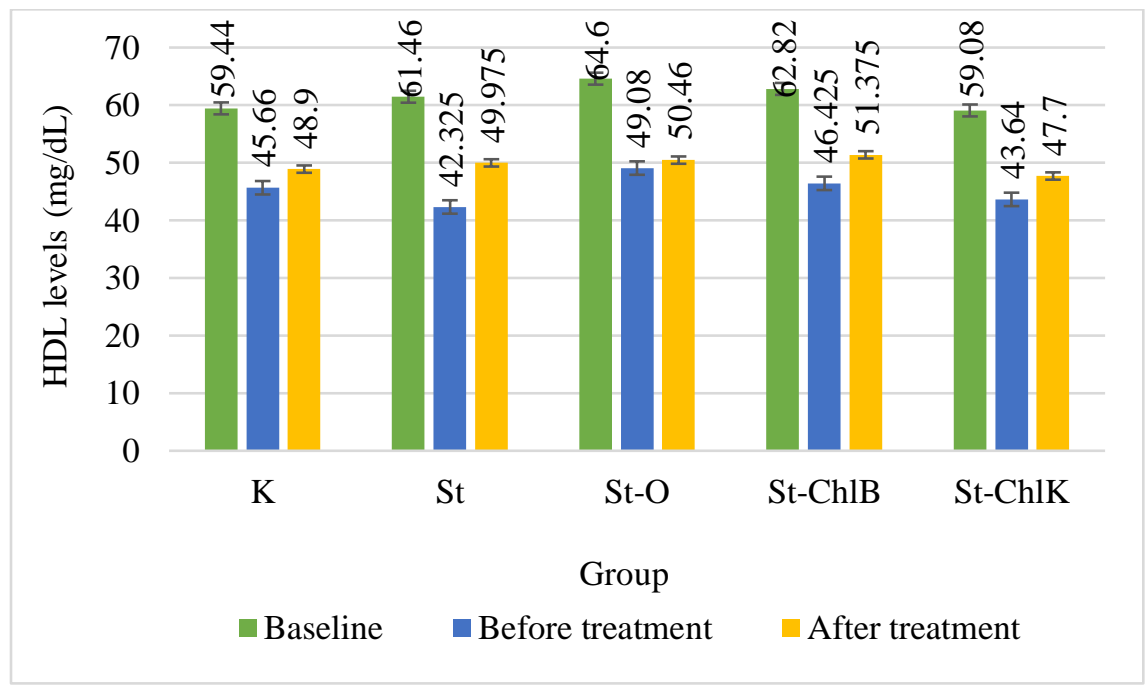

Figure 4. The mean of HDL levels of mice (Rattus norvegicus Berkenhout, 1769) wistar strain with the treatment of Chlorella vulgaris

The following table lists the percentage of HDL levels increment of rats (Rattus norvegicus Berkenhout, 1769) wistar strain with the treatments appropriate their group.

Table 5. Percentage of HDL levels increasement of rats (Rattus norvegicus Berkenhout, 1769) wistar strain

\begin{tabular}{|c|c|c|}
\hline \multirow{2}{*}{ Treatment } & \multicolumn{2}{|c|}{ HDL level } \\
\hline & Difference $(\mathrm{mg} / \mathrm{dL})$ & Percentage $(\%)$ \\
\hline Without treatment & 3.24 & 7 \\
\hline Stress & 7.65 & 18 \\
\hline Stress with antidepressant medicine & 1.38 & 3 \\
\hline Stress with Chlorella vulgaris cultivation & 4.95 & 11 \\
\hline Stress with Chlorella sp. commercial & 4.06 & 9 \\
\hline
\end{tabular}

The highest HDL increasement level owned by stress group of $7.65 \mathrm{mg} / \mathrm{dL}$ (Table 5) with the increasement of $18 \%$ followed by stress group with Chlorella vulgaris cultivation (11\%), stress with Chlorella sp. commercial (9\%), control group (7\%) and stress group with antidepressant medicine (3\%). Then analyzed using One Way ANOVA test, that obtained results in following table (Table 6) that HDL cholesterol levels between groups experienced an insignificantly different increase ( $p>0.05 ; p$ $=0.979$ ).

From table 5 it can be seen that group induced by stress the treat by antidepressant medicine, Chlorella vulgaris cultivation and Chlorella sp. commercial, the increasement of percentage of HDL level was smaller that control group and stress group. Seen by group than induced by stress and then treat, the highest increase in the percentage of HDL levels was held by the stress group with Chlorella vulgaris cultivation by $11 \%$ followed by the stress group with Chlorella sp. commercial $9 \%$ and the stress group with antidepressant medicine by $\%$. Giving Chlorella sp. both cultivation and commercial can increase the percentage of HDL levels. Chlorella $\mathrm{sp}$. These results happened because Chlorella contains omega-3 fatty acids affecting the decrease in HDL levels (Connor, 2000). 


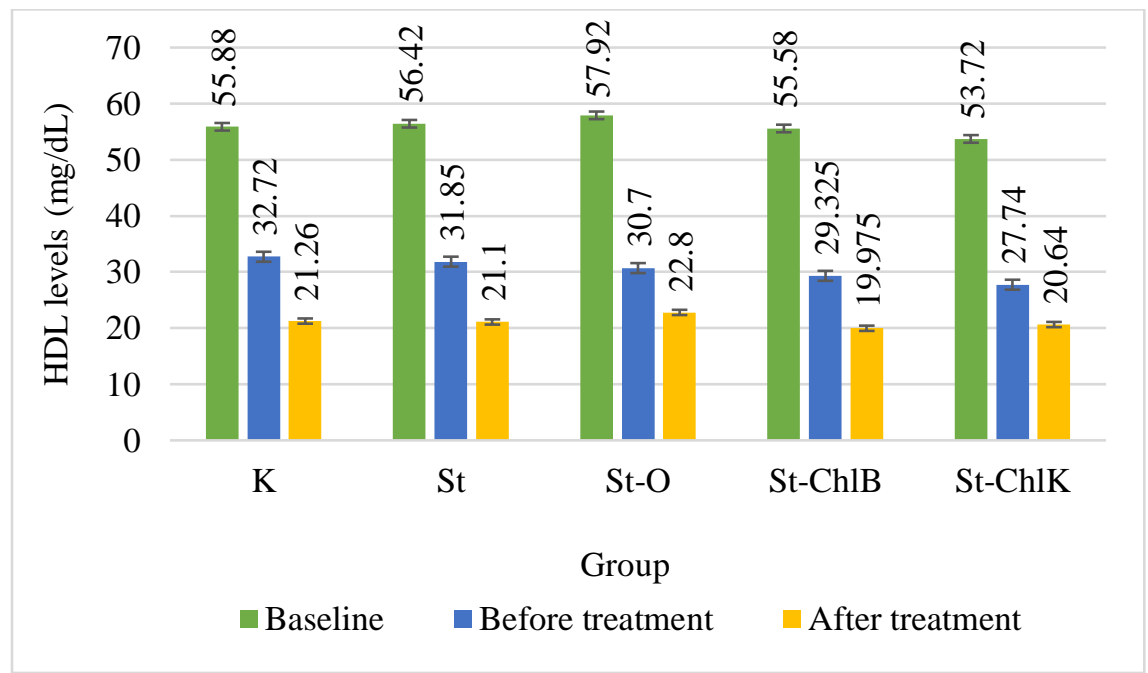

Figure 5. The mean of LDL level of rats (Rattus norvegicus Berkenhout, 1769) wistar strain with treatment

The table lists of the reduction level percentage of rats' LDL (Rattus norvegicus Berkenhout,
1769) with the treatments approriate to their group.

Table 6. Reduction level percentage of rats' LDL (Rattus norvegicus Berkenhout, 1769)

\begin{tabular}{lcc}
\hline \multicolumn{1}{c}{ Treatment } & \multicolumn{2}{c}{ LDL Level } \\
\cline { 2 - 3 } & Difference (mg/dL) & Percentage $(\%)$ \\
\hline Control & -11.46 & -35 \\
\hline Stress & -10.75 & -34 \\
\hline Stress with antidepressant medicine & -7.9 & -26 \\
\hline Stress with Chlorella vulgaris cultivation & -9.35 & -32 \\
\hline Stress with Chlorella sp. commercial & -7.1 & -26 \\
\hline$(-)$ indicates reduction & &
\end{tabular}

From table 6 it can be seen that group induced by stress then treat by giving antidepressant medicine, Chlorella vulgaris cultivation, and Chlorella sp. commercial experienced reduction on the LDL level percentage smaller than control group and stress group. Seen by the group that induced by stress then was having a treatment, the highest LDL reduction level percentage owned by stress group with Chlorella vulgaris cultivation of $32 \%$ followed by stress group with antidepressant medicine and stress group with Chlorella sp. commercial of same value $26 \%$. Giving Chlorella sp. both cultivation and commercial can reduce the percentage of LDL levels. These results were in line with the research that has been done previously by other researchers.

LDL level reduction by Chlorella sp. started in lipoprotein lipolytic cascade, started with lipoprotein lipolytic cascades, apo B was needed for VLDL secretion from the liver and was converted to intermediate-density lipoprotein (IDL) by lipoprotein lipase on the surface of capillary endothelium (EbrahimiMameghani et al., 2015; Li et al., 2014). IDL particles can be quickly extracted and then catabolized especially in the liver via apo E, a high-affinity ligand for receptors (Zambon et al., 2003; Cohen, 2013). However, some IDL particles escaped hepatic uptake and remained in circulation due to a lack of $E$ apo and subsequently converted to LDL (Dbobková et al., 2004; Zheng et al., 2007; Dithmar et al., 2000). B's binding affinity for apo is relatively low, and as such, LDL particles circulate for a relatively long period before binding to LDL receptors throughout the body. Generally, there was only one B for each LDL particle. Thus, the level of plasma apo B was strongly related to the number of LDL particles, which is an important detector of the risk of cardiovascular disease. Conversely, HDL receives cholesterol from peripheral cells and transports it to the 
liver for bile production. Apo A1 is the main protein constituent of HDL particles, mediating transport back cholesterol. The most prominent effect of Chlorella is a decrease in the concentration of VLDL and apo B. This result implies that there is secretion of apo $\mathrm{B}$ and VLDL which slow down into the circulation or catabolism of VLDL which is faster in the liver. Therefore, by decreasing apo B, LDL levels can also decrease (Ryu et al., 2014).

\section{CONCLUSION}

Stress induction affecter to blood lipid profile of wistar strain rats, that is triglyceride level increment and HDL level and LDL level reduction, also total cholesterol level reduction besides the control group. Giving Chlorella vulgaris affected the reduction of total cholesterol level, triglyceride level and LDL level and increment in HDL level.

\section{ACKNOWLEDGMENTS}

We thank the Integrated Research and Testing Laboratory of Gadjah Mada University (LPPTUGM Unit I \& IV) for providing experimental animals and facilitating this research. Thanks to the colleague of the research partner for the teamwork, Gisella Intan Soetantyo.

\section{REFERENCES}

Balkan J, Doğru-Abbasoğlu S, Aykaç-Toker G, Uysal M. 2004. The effect of a high cholesterol diet on lipids and oxidative stress in plasma, liver and aorta of rabbits and rats. Nutrition Research. vol 24(3): 229-234.

doi: https://doi.org/10.1016/j.nutres.2003.10.0 05 .

Cohen DE. 2013. Lipoprotein Metabolism, Dyslipidemia, and Nonalcoholic Fatty Liver Disease. Semin Liver Dis. vol 33(04): 380-388. doi: 10.1055/s-0033-1358519.

Connor WE. 2000. Importance of n-3 fatty acids in health and disease. Am J Clin Nutr 71:171S-175S.

Das D. 2015. Algal Biorefinery: An Integrated Approach.New York: Springer. p. 37.

Dbobková D, Honsová E, Kováŕ J, Poledne R. 2004. Effect of Diets on Lipoprotein Concentrations in Heterozygous
Apolipoprotein E-Deficient Mice. Physiol. Res. vol 53: 635-643.

Dithmar S, Curcio CA, Le NA, Brown SS, Grossniklaus HE. 2000. Ultrastructural Changes in Bruch's Membrane of Apolipoprotein E-Deficient Mice. Anatomy and Pathology/Oncology. vol 41(8): 2035-2042.

Ebrahimi-Mameghani M, Aliashrafi S, Javadzadeh Y, Jafarabadi MA. 2014. The Effect of Chlorella vulgaris Supplementation on Liver Enzymes, Serum Glucose and Lipid Profile in Patients with Non-Alcoholic Fatty Liver Disease. Health Promot Perspect. vol 4(1): 107-115. doi: https://dx.doi.org/10.5681\%2Fhpp.2014.0 14.

Fretes H, Susanto AB, Prasety B, Limantara L. 2012. Karotenoid dari Makroalga dan Potensi Kesehatan Aplikasi dan Bioteknologi. Jurnal Teknologi dan Industri Pangan. vol 23(2): 221.

Lee HS, Park HJ, Kim MK. 2008. Effect of Chlorella vulgaris on lipid metabolism in Wistar rats fed high fat diet. Nutrition Research and Practice. vol 2(4):204-210. doi: https://doi.org/10.4162/nrp.2008.2.4.204.

Li H, Dhanasekaran P, Alexander ET, Rader DJ, Phillips MC, Lund-Katz S. 2014. Molecular mechanisms responsible for the differential effects of apoE3 and apoE4 on plasma lipoprotein cholesterol levels. Arterioscler Thromb Vasc Biol. vol 33(4): 687-693. doi: https://dx.doi.org/10.1161\%2FATVBAH A.112.301193.

Nagaraja HS, Anupama BK, Jeganathan PS. 2006. Stress Response in Albino Rats. Thai journal of physiological sciences. vol 19(2): 8-15.

Otles S, and Pire R. 2001. Fatty Acid Composition of Chlorella and Spirulina Microalgae Species. Journal of AOAC International. vol 84(6): 1708-1714.

Queenan KM, Stewart ML, Smith KN, Thomas W, Fulcher RG, Slavin JL. 2014. Concentrated oat beta-glucan, a fermentable fiber, lowers serum 
cholesterol in hypercholesterolemic adults in a randomized controlled trial. Nutrition Journal. vol 6(6): 1-8. doi: https://doi.org/10.1186/1475-2891-6-6.

Ryu NH, Lim Y, Park JE, Kim J, Kim JY, Kwon SW, Kwon O. 2014. Impact of daily Chlorella consumption on serum lipid and carotenoid profiles in mildly hypercholesterolemic adults: a doubleblinded, randomized, placebo-controlled study. Nutrition Journal. vol 13(57): 1-8. doi: https://doi.org/10.1186/1475-289113-57.

Salem SA. 2015. Effect of two carotenoids (Lycopene and $\beta$-Carotene) supplementation on hyperlipidemia and lipid peroxidation in experimental albino rats. Journal of High Institute of Public Health. vol 45(1): 1-7.

Serchov T, van Calker D, Biber K. 2016. Sucrose Preference Test to Measure Anhedonic Behaviour in Mice. Bioprotocol. vol 6(19): e1958. doi: 10.21769/BioProtoc.1958.

Shibata S, Oda K, Onodera-Masuoka N, Matsubara S, Kikuchi-Hayakawa H, Ishikawa F, Iwabuchi A, Sansawa H. 2001. Hypocholesterolemic effect of indigestible fraction of Chlorella regularis in cholesterol-fed rats. J Nutr Sci Vitaminol. vol 47(6): 373-377. doi: https://doi.org/10.3177/jnsv.47.373.

Watto FH., Memon MS, Memon AN, Wattoo MHS, Tirmizi SA, Iqbal J. 2008. Estimation and correlation of stress and cholesterol levels in college teachers and housewives of Hyderabad-Pakistan. J Pak Med Assoc. vol 58(1): 15-18.

Wirosaputro S, dan Sumarlini T. 2016. Chlorella Makanan Kesehatan Global Alami. Yogyakarta: Gadjah Mada University Press. hal. 42-59.

Zambon A, Bertocco S, Vitturi n, Polentarutti V. 2003. Relevance of hepatic lipase to the metabolism of triacylglycerol-rich lipoproteins. Biochemical Society Transactions. vol 31(5): 1070-1074. doi: 10.1042/bst0311070.

Zheng C, Khoo C, Ikewaki K, Sacks FM. 2007. Rapid turnover of apolipoprotein C-IIIcontaining triglyceride-rich lipoproteins contributing to the formation of LDL subfractions. The Journal of Lipid Research. vol 48:1190-1203. doi: 10.1194/jlr.P600011-JLR200. 